\title{
In vitro anti-inflammatory, anti-arthritic and anti- proliferative activity of green synthesized silver nanoparticles - Phoenix dactylifera (Rothan dates)
}

\author{
Syed Zameer Ahmed Khader', Sidhra Syed Zameer Ahmed ${ }^{\circledR \text { 1* }}$ \\ Mohamed Rafi Mahboob², Selva Barathi Prabaharan', \\ Shanmugasundaram Olapalayam Lakshmanan, \\ Kishore Ramesh Kumar ${ }^{1}$, Daniel David ${ }^{1}$
}

${ }^{1}$ Department of Biotechnology, K.S.Rangasamy College of Technology, K.S.R. Kalvinagar, Tiruchengode, Tamil Nadu, India, ${ }^{2}$ Department of Physics, C. Abdul Hakeem College, Melvisharam, Vellore, Tamil Nadu, India, ${ }^{3}$ Department of Textile Technology, K.S.Rangasamy College of Technology, Tamil Nadu, India

\begin{abstract}
Traditionally dates is consumed as a rich source of iron supplement and the current research discuss the synthesis of silver nanoparticles (AgNPs) using methanolic seed extract of Rothan date and its application over in vitro anti-arthritic, anti-inflammatory and antiproliferative activity against lung cancer cell line (A549). FTIR result of synthesised AgNPs reveals the presence of functional group $\mathrm{OH}$ as capping agent. XRD pattern confirms the crystalline nature of the AgNPs with peaks at $38^{\circ}, 44^{\circ}, 64^{\circ}$ and $81^{\circ}$, indexed by (111), (200), (220) and (222) in the $2 \theta$ range of $10-90$, indicating the face centered cubic (fcc) structure of metallic Ag. HRTEM results confirm the morphology of AgNPs as almost spherical with high surface areas and average size of $42 \pm 9 \mathrm{~nm}$. EDX spectra confirmed that Ag is only the major element present and the Dynamic light scattering (DLS) assisted that the $Z$-average size was $203 \mathrm{~nm}$ and 1.0 of PdI value. Zeta potential showed $-26.5 \mathrm{mv}$ with a single peak. The results of the biological activities of AgNPs exhibited dose dependent activity with $68.44 \%$ for arthritic, antiinflammatory with $63.32 \%$ inhibition and anti-proliferative activity illustrated $\mathrm{IC}_{50}$ value of $59.66 \mu \mathrm{g} / \mathrm{mL}$ expressing the potential of AgNPs to combat cancer.
\end{abstract}

Keywords: Nanoparticles. Proliferation. Inflammatory. Arthritic. Green synthesis. Anticancer.

\section{INTRODUCTION}

Nano-biotechnology is a developing area of research that inculcates the application of nano-materials in the field of biomedical research as their improved properties are leading to the rapid development and discoveries in the medical, optics and electronic industries. The recent advancements of nano-materials are based on explicit characteristics such as size, distribution and morphology (Packialakshmi, Suganya, Guru, 2014; Rafi et al., 2015). Green synthesis is a process of nanomaterial fabrication

*Correspondence: S. Sidhra. Department of Biotechnology. K.S. Rangasamy College of Technology. K.S.R. Kalvinagar. Tiruchengode 637 215, Tamil Nadu, India. Phone: + 91-9865256782, +91-8925606633. E-mail:sidhrazameer@gmail.com; zameerkhader@gmail.com following eco-friendly and sustainable approaches without usage of any toxic chemicals. Various biological entities like plant extracts, bacteria, algae, fungi, lichens and enzymes are used for green synthesis of nanoparticles (Dhand et al., 2016).

Green synthesis of nanoparticles are specific due to their ability in shape confinement due to the diversified chemical, optical and electrical properties (Jayaseelana et al., 2013). Silver nanoparticle synthesis is notably interesting due to their application in the field of drug delivery, energy systems and optics because of their surface properties. These silver nanoparticles are clinically used in cancer treatment and diagnosis. Generally, nanoparticles preparation involves chemical and physical methods that are expensive and emits hazardous chemicals to the environment causing pollution 
and various biological risks. The recent development of biotechnological processes for nanoparticle synthesis is evolving as the plant phytoconstituents can act as both reducing and capping agents (Ahmed et al., 2016).

Green synthesized nanoparticles are predominantly accepted in pharmaceutical industry, due to its safe and zero side effect property. Since there is a rising interest in discovering the novel phytochemical correlating to its pharmacological activity as this study focus on understanding the bioactive functions of the dates seed extract. The antioxidant activity is studied to evaluate the potential of the AgNPs in reducing the oxidative stress and disease progression which is further compared with its anti-proliferative effect against cancer cells. The inter relation between arthritis and inflammation is that both are tissue destruction caused by immune complexes, however synthesised AgNPs are capable of controlling it effectively when compared with the standard drugs.

Phoenix dactylifera (Rothan variety), commonly known as "date palm", is cultivated in various parts of Asia for its delicious fruits as well as medicinal importance. The date fruit contains phytochemicals like carbohydrates, proteins, sterols, flavonoids, anthocyanins and phenolics, mainly cinnamic acid derivatives (Farhadi et al., 2017) thus resulting in the reducing property of the extract. Present work deals with the synthesis of AgNPs from the seed extract of Phoenix dactylifera without any extra stabilizing or capping agents (Shib et al., 2013) and to investigate the in-vitro biological activities.

\section{MATERIAL AND METHODS}

\section{Material}

All chemicals, reagents, medium components are procured from Merck, India. Phoenix dactylifera (Rothan) fruits were procured from local market at Al Majmaah, Kingdom of Saudi Arabia, seeds were removed from flesh, shade dried then rinsed with water three times and then cleansed with Milli-Q water to remove the fine dust particles. Finally the seeds were air dried for one week to remove all moisture completely, coarsely powdered, packed in air tight container and stored under normal temperature for further use (Syed Zameer Ahmed et al., 2019a).

\section{Preparation of seed extract from Phoenix dactylifera (Rothan)}

The powdered Phoenix dactylifera (Rothan) seeds were taken and methanolic extract was prepared using soxhlet's apparatus by adding $10 \mathrm{~g}$ of seed powder and refluxed with $200 \mathrm{~mL}$ methanol for 6 hours. The extract was then cooled at room temperature and filtered with Whatman No.1 filter paper to yield a deep brown coloured filtrate (Shib et al., 2013).

\section{Synthesis of silver nanoparticles (AgNPs)}

For the synthesis of the AgNPs, $20 \mathrm{~mL}$ of seed extract was added to $50 \mathrm{~mL}$ of analytical grade $\mathrm{AgNO}_{3}$ solution $\left(10^{-3} \mathrm{M}\right)$ and the volume was adjusted to $180 \mathrm{~mL}$ with de-ionized water. The flask was then incubated at room temperature for 24 hours and observed for change in colour intensity (Baghizadeh et al., 2015).

\section{Characterization of synthesized AgNPs}

The AgNPs synthesized from Rothan date seeds were processed suitably for characterization studies. The reducing components of phytochemical extract was found by Fourier Transform-Infrared Spectroscopy (FTIR 8400) in solid state. The morphology of AgNPs were analysed using HR-TEM (High resolution-Transmission emission of microscopy) and the crystalinity of AgNPs was examined using Bruker AXS D8 Advance X-ray Diffractometer (XRD) and Energy-Dispersive X-Ray Spectroscopy Analyser (EDXA: Oxford Link ISIS300), Zeta potential and hydrodynamic diameter of nanoparticles were determined by dynamic light scattering using Malvern Zeta-sizer Nanoseries (UK).

\section{In vitro free radical scavenging activity on synthesized AgNPs DPPH radicals scavenging assay}

DPPH assay is commonly used to determine the free radical scavenging ability. Shimada et al., (1992) method with minor modifications was used to screen the free radical scavenging activity of AgNPs. The 
reaction mixture consisted of $1.0 \mathrm{~mL}$ AgNPs varying concentration $(2,5,10 \mathrm{mg} / \mathrm{mL})$ mixed with $1.0 \mathrm{~mL}$ of 0.8 $\mathrm{mM} / \mathrm{L}$ DPPH solution and incubated at room temperature for 30 min under shaking condition. Then absorbance was recorded at $517 \mathrm{~nm}$ against gallic acid as control. The inhibition percentage for scavenging of DPPH radical was calculated by the following formula.

\section{Ferric ions (Fe3+) reducing antioxidant power assay (FRAP)}

The ferric ion reducing power of AgNPs was analysed by the method of Oyaizu. (1986) with minor modification. The reaction mixture consisted of 2,5 , $10 \mathrm{mg} / \mathrm{mL}$ of AgNPs was diluted with $2.5 \mathrm{~mL}$ of $0.2 \mathrm{M}$ phosphate buffer ( $\mathrm{pH}$ 6.6) followed by $2.5 \mathrm{~mL}$ of $1 \%$ potassium ferricyanide $\left[\mathrm{K}_{3} \mathrm{Fe}(\mathrm{CN})_{6}\right]$ and incubated at $50^{\circ} \mathrm{C}$ for $20 \mathrm{~min} .2 .5 \mathrm{~mL}$ of $10 \%$ trichloroacetic acid was added and centrifuge at $3000 \mathrm{rpm}$ for $10 \mathrm{~min}$. Finally $2.5 \mathrm{~mL}$ of supernatant was mixed with $2.5 \mathrm{~mL}$ of deionized water and $0.5 \mathrm{~mL}$ of $0.1 \% \mathrm{FeCl}_{3}$. The absorbance at $700 \mathrm{~nm}$ was measured against ascorbic acid as positive control.

\section{Hydroxyl radical scavenging assay}

The hydroxyl radical scavenging activity was performed by Halliwell et al., (1987) method with minor modification. Prepare stock solutions of EDTA $(1 \mathrm{mM})$, $\mathrm{FeCl}_{3}(10 \mathrm{mM})$, ascorbic acid $(1 \mathrm{mM}), \mathrm{H}_{2} \mathrm{O}_{2}(10 \mathrm{mM})$ and deoxyribose $(10 \mathrm{mM})$ in distilled deionized water. The reaction mixture was prepared with $0.1 \mathrm{~mL}$ of EDTA, $0.01 \mathrm{~mL}$ of $\mathrm{FeCl}_{3}, 0.1 \mathrm{~mL}$ of $\mathrm{H}_{2} \mathrm{O}_{2}, 0.36 \mathrm{~mL}$ of deoxyribose, $1.0 \mathrm{~mL}$ of AgNPs extract $(2,5,10 \mathrm{mg} / \mathrm{mL}), 0.33 \mathrm{~mL}$ of phosphate buffer $(50 \mathrm{mM}, \mathrm{pH} 7.4), 0.1 \mathrm{~mL}$ of ascorbic acid in sequence and then incubated at $37^{\circ} \mathrm{C}$ for $1 \mathrm{hr}$. Finally $1.0 \mathrm{~mL}$ of the mixture was taken separately mixed with $1.0 \mathrm{~mL}$ of $10 \%$ TCA and $1.0 \mathrm{~mL}$ of $0.5 \%$ TBA. The final mixture was measure at $532 \mathrm{~nm}$.

\section{Hydroxyl scavenging activity $(\%)=(\mathrm{A} 0-\mathrm{A} 1 / \mathrm{A} 0) \times 100)$}

(A1 is the absorbance of standards or reaction mixture, $\mathrm{A} 0$ is the absorbance of the negative control).

\section{Anti-arthritic activity (protein denaturation assay) of synthesized AgNPs}

Anti-arthritic activity of the AgNPs was determined using the method of Deshpande et al., (2009) with minor modifications. The reaction mixture consisted of the $100 \mu \mathrm{l}$ AgNPs extracts (final concentrations $100,250,500 \mu \mathrm{g} / \mathrm{mL}$ ) and $100 \mu \mathrm{l}$ of $5 \%$ aqueous solution of bovine serum albumin (BSA); $\mathrm{pH}$ was adjusted using $1 \mathrm{~N} \mathrm{HCl}$. The test samples were kept for incubation at $37{ }^{\circ} \mathrm{C}$ for $20 \mathrm{~min}$ and heated to $57^{\circ} \mathrm{C}$ for $3 \mathrm{~min}$. The mixture was allowed to cool for $10 \mathrm{~min}$ after which absorbance was measured at $416 \mathrm{~nm}$. The blank comprise of the sample and distilled water was used as the negative control. The positive control was diclofenac sodium (final concentration 100, 250, 500 $\mu \mathrm{g} / \mathrm{mL}$ ). Percentage inhibition was calculated using the formula:

\section{Anti-inflammatory activity of synthesized AgNPs}

The anti-inflammatory method of Mizushima and Kobayashi (1968) was used for inhibition of albumin denaturation. The reaction mixture consisting of (100 $\mu \mathrm{g} / \mathrm{mL}, 250 \mu \mathrm{g} / \mathrm{mL}$, and $500 \mu \mathrm{g} / \mathrm{mL}$ ) of AgNPs extract is taken with $1 \%$ aqueous solution of bovine albumin fraction and the $\mathrm{pH}$ was maintained at 6.3 using $1 \mathrm{~N} \mathrm{HCl}$. The reaction mixture was incubated at $37^{\circ} \mathrm{C}$ for $20 \mathrm{~min}$ and then temperature was increased to $51^{\circ} \mathrm{C}$ for $20 \mathrm{~min}$ further allowed to cool. The absorbance of the mixture was measured spectrophotometrically at $660 \mathrm{~nm}$ and their results were compared with standard drug Diclofenacsodium $(100,250,500 \mu \mathrm{g} / \mathrm{mL})$. Percentage inhibition of protein denaturation was calculated by

\section{$\%$ Stabilization $=100-[$ A1 $($ sample $/$ standard $) / \mathrm{A0}$ (control) x 100]}

Where A1 was the absorbance in the presence of the sample/standard (Diclofenac sodium) and A0 was the absorbance of the control reaction 


\section{In vitro anticancer activity for synthesised AgNPs Cell lines and culturing}

Human lung adeno carcinoma cell lines (A549) was obtained from National Centre for Cell Sciences (NCCS), Pune, India. A549 cell line were cultured in DMEM (Dulbecco's modifications of Eagle's medium with L-glutamine \& 4.5G/L glucose) supplemented with fetal bovine serum, 100 units $/ \mathrm{mL}$ of penicillin $\mathrm{G}$ and $(0.1 \mathrm{mg} / \mathrm{mL})$ of streptomycin sulphate in a humidified atmosphere of a $5 \% \mathrm{CO}_{2}$ at $37^{\circ} \mathrm{C}$.

\section{MTT Assay for cell viability}

The MTT assay was used to measure cell viability. The MTT substrate is prepared in a physiologically balanced solution, added to cells in culture, usually at a final concentration of $0.2-0.5 \mathrm{mg} / \mathrm{mL}$, and incubated for 1 to 4 hours. The quantity of formazan (presumably directly proportional to the number of viable cells) is measured by recording changes in absorbance at 570 $\mathrm{nm}$ using a microtiter plate reader. Viable cell converts MTT into a purple coloured formazan product due to the active metabolism with an absorbance maxima near $570 \mathrm{~nm}$. The cells lose the ability to convert MTT into formazan when they are dead, thus colour formation acts as a useful and suitable marker for the viable cells. Thus cell survival is calculated by the formula.

\section{RESULTS AND DISCUSSION}

\section{Characterization of synthesised AgNPs FTIR interpretation}

FTIR spectroscopy studies were carried out to investigate the presence of biomolecules responsible for the reduction and capping of the AgNPs synthesized by Rothan date seed extract is shown in Figure 1. The peak at $3450.8 \mathrm{~cm}^{-1}$ is attributed to stretching vibration of O-H / N-H functionality and broad area indicating the intermolecular hydrogen bonding. The peaks at $2924 \mathrm{~cm}^{-1}$ is due to saturated C-H stretching vibration. The presence of peaks at 1619.3 and $1383.9 \mathrm{~cm}^{-1}$ region might be due to aromatic $\mathrm{C}=\mathrm{C}$ stretching vibration. These peaks mainly belongs to the flavonoids and terpenoids in the plant extracts and is responsible for reduction of silver ions to silver nanoparticles by the plant extracts (Banerjee et al., 2014; Khader et al., 2018a), hence Rothan date seed extracts act as capping agent to produce silver nanoparticles. According to Haghighi Pak et al. (2016) both FTIR spectra show a shift in peaks: 1401-1396 (due to C-C in-ring stretching of aromatic amines) and in this investigation the peak was observed at 1619.3 and $1383.9 \mathrm{~cm}^{-1}$, it conforms the presence of aromatic amines.

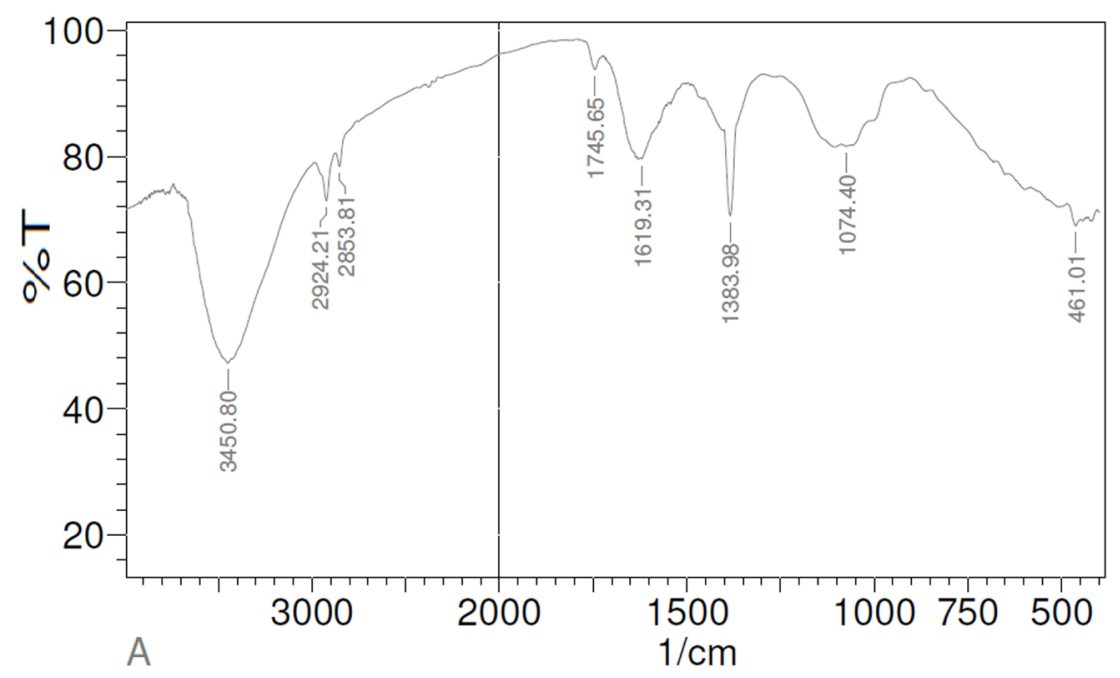

FIGURE 1 - Fourier transform infrared (FTIR) spectra of AgNPs synthesized from Rothan date seed extract. 


\section{X-ray diffraction measurements}

$\mathrm{XRD}$ is a prompt investigative technique predominantly used for phase identification of a crystalline substance that can provide data on unit cell dimensions. The analysed material is finely ground, homogenised, and bulk composition is determined. The XRD pattern of silver nanoparticles of Rothan seed extract is illustrated in Figure 2. Three diffraction peaks as (111), (200), (220), and (222) were observed in the $2 \theta$ range of 10-90, indicated expressions of face centered cubic (fcc) structure metallic Ag, representing as a pure crystalline Ag (Khader et al., 2018a). The AgNPs was formed by the reduction of $\mathrm{Ag}^{+}$ions by Rothan date seeds exudate are crystalline in nature which were confirmed by XRD pattern.

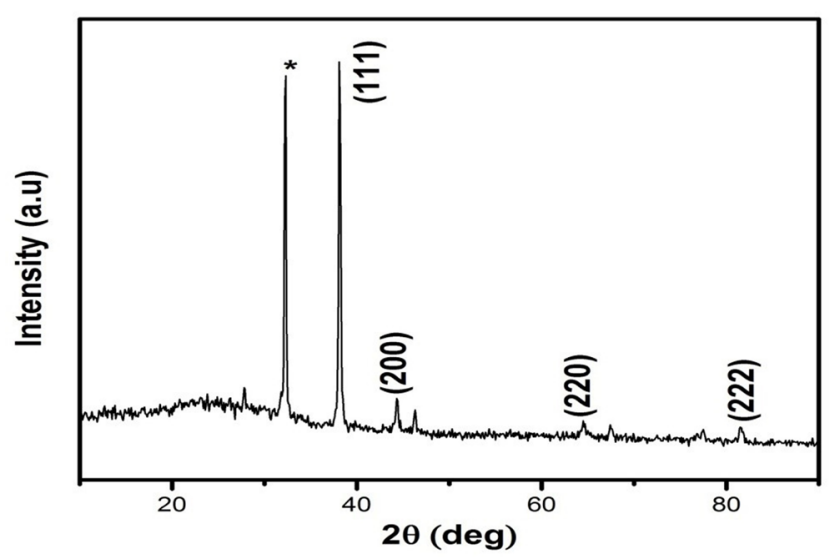

FIGURE 2 - XRD pattern of AgNPs synthesized from Rothan date seed extract.

\section{High resolution-transmission electron microscopy interpretation}

HR-TEM is an imaging mode of the transmission electron microscope that permits direct imaging of the atomic structure of the sample. HR-TEM is an instrument used to study the selected area electron diffraction (SAED) pattern (Figure 3e) which is in accordance with XRD studies. The resulted images were examined to provide insight on the morphological characteristics present in silver nanoparticles of
Rothan date seed extract. The size and morphology of synthesized AgNPs with Rothan date seeds were determined by TEM images, as shown in Figure 3(ad). The morphology of AgNPs is almost spherical, and exhibited high surface areas with average size of $42 \pm 9 \mathrm{~nm}$. The particles are arranged in poly dispersity based on particle size, functionalized with biomolecules having primary amine group, carbonyl group, hydroxyl groups and other stabilizing functional groups as shown by FTIR spectroscopic technique which is in line with Shankar et al., (2004).
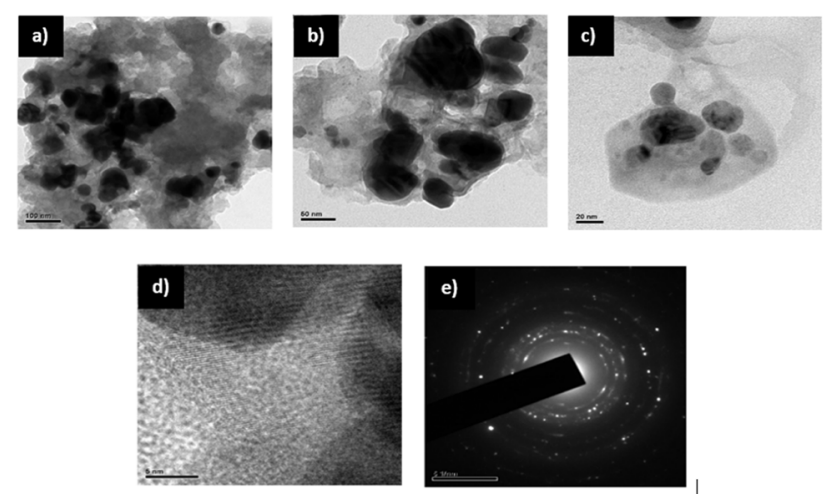

FIGURE 3 - (a-d). HRTEM images and (e) SAED pattern of synthesized AgNPs with Rothan date seed extract in different magnifications.

\section{Energy dispersive X-ray spectroscopy results}

Energy dispersive X-ray spectroscopy is an analytical technique used for the elemental analysis of a sample. Its characterisation abilities are due to the important principle that each element has a unique atomic structure allowing a unique set of peaks on its electromagnetic spectrum. The presence of elemental silver in Rothan date seed extract was confirmed by EDX analysis where optical absorption peak was observed approximately at $2.95 \mathrm{kV}$. This is the typical value for the absorption of metallic silver nano-crystallites due to surface plasmon resonance and the amount of silver being 21.68\%. As shown in Figure 4, the EDX results indicate that $\mathrm{Ag}$ is the only major element present in as-prepared sample. The insignificant amounts of observed $\mathrm{Mg}, \mathrm{Si}$, $\mathrm{S}$ and $\mathrm{Ca}$ are attributed to the plant biomass attached to the AgNPs. 


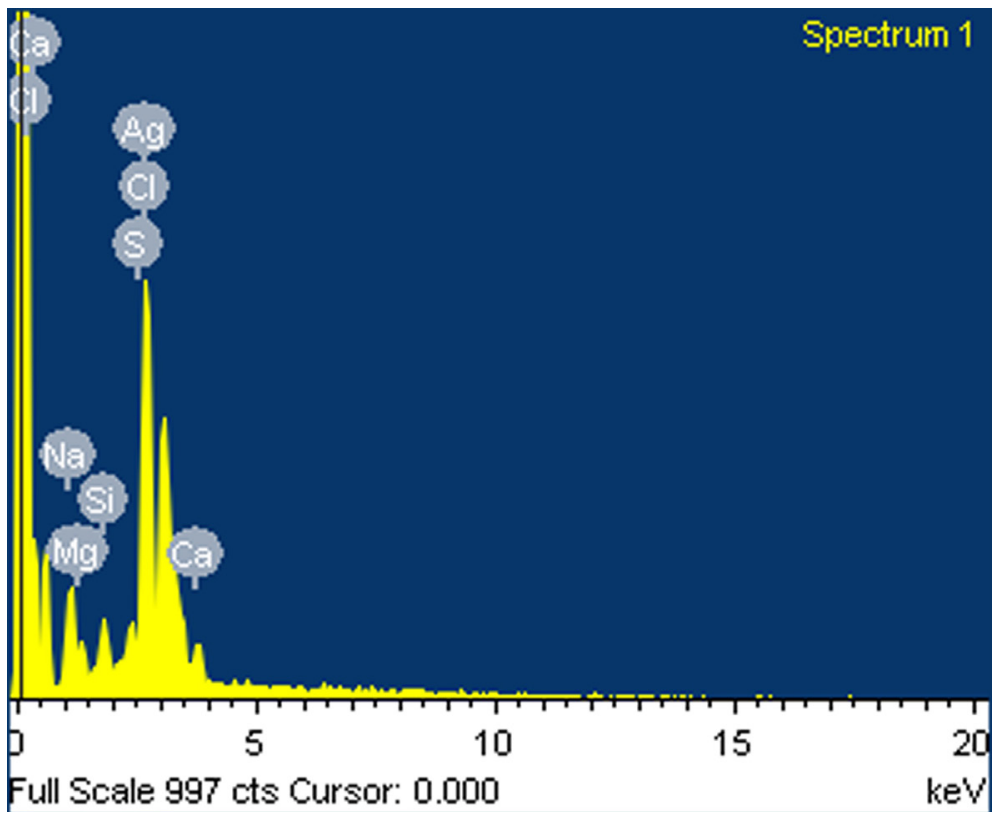

FIGURE 4 - EDX spectrum of AgNPs synthesized from Rothan date seed extract.

\section{Zeta potential measurements of synthesized AgNPs}

The most important characterizations of the silver nanoparticles are the Particle size, size distribution and zeta potential because they oversee the other characterizations, such as saturation solubility and dissolution velocity, physical stability, or even biological performances. The zeta potential and hydrodynamic diameter of synthesized silver nanoparticles from Rothan date seed extract were determined by DLS is shown in Figure $5(\mathrm{a}, \mathrm{b})$. The measured zeta value $(\zeta)$ was found to be $-26.5 \mathrm{mv}$ and it showed long term stability with good colloidal nature and high dispersity index of the synthesized silver nanoparticles. The hydrodynamic diameter of the synthesized nanoparticles was $203 \mathrm{~nm}$ and it is observed that the particles obtained are polydisperse mixture (Roy et al., 2019). (a)

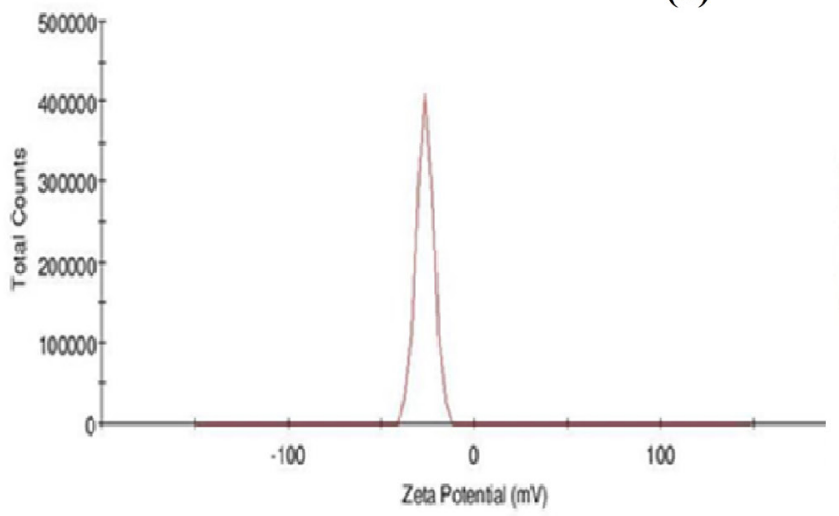

(b)

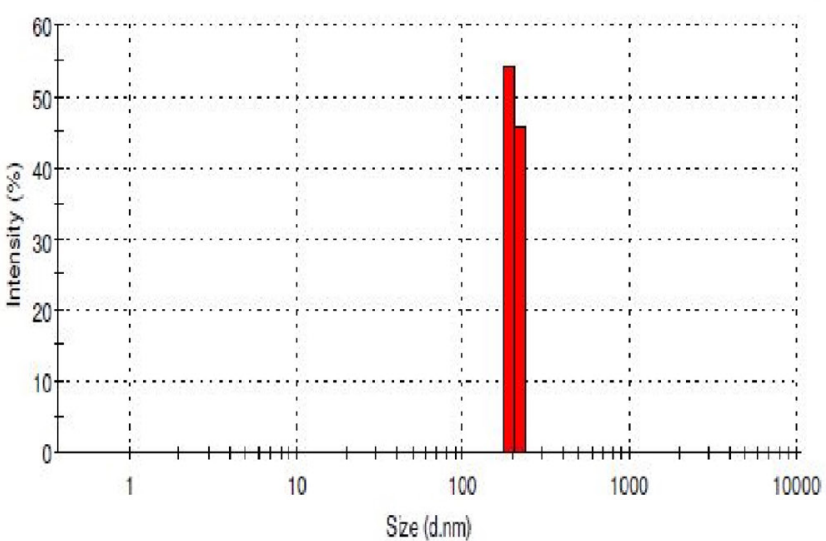

FIGURE 5 - (a, b). Zeta potential and hydrodynamic diameter of synthesized silver nanoparticles from Rothan date seed extract. 


\section{Effect of in vitro radical scavenging activity of AgNPs}

Radical scavenging activity of AgNPs was assessed using DPPH, FRAP and $\mathrm{OH}$ radical scavenging activity (Figure 6) and the results are interpreted in \% inhibition. From the performed DPPH assay it was found that AgNPs extract was capable of neutralizing the DPPH free radicals via hydrogen donating activity at different levels. The scavenging activity was dose dependent as the concentration of AgNPs extracts increases scavenging ability improves. Minimum scavenging activity was found at the concentration of $2 \mathrm{mg}$ with $22 \%$ inhibition and the maximum inhibition was observed at concentration $10 \mathrm{mg}$ with $64 \%$ inhibition. The reducing ability (FRAP) of AgNPs is represented in Figure 6, demonstrating dose dependent activity at higher concentration with $79.2 \%$. Similarly, the results of hydroxyl radical scavenging activity demonstrates that AgNPs synthesised from dates extract exhibited maximum activity $(78.7 \%)$ at $10 \mathrm{mg}$ concentration (Figure 6). Many research has stated that various medicinal plants and their products has confirmed to be a potential to radical scavenger and has the ability to combat against various diseases (Khader et al., 2018b; Syed et al., 2019b; Sidhra et al., 2017). DPPH, FRAP and $\mathrm{OH}$ radicals are frequently used in research to identify the scavenging potential, in the present study the radicals produced are scavenged by the synthesized AgNPs from Rothan date seeds by donating electrons and making it a more stable compound.

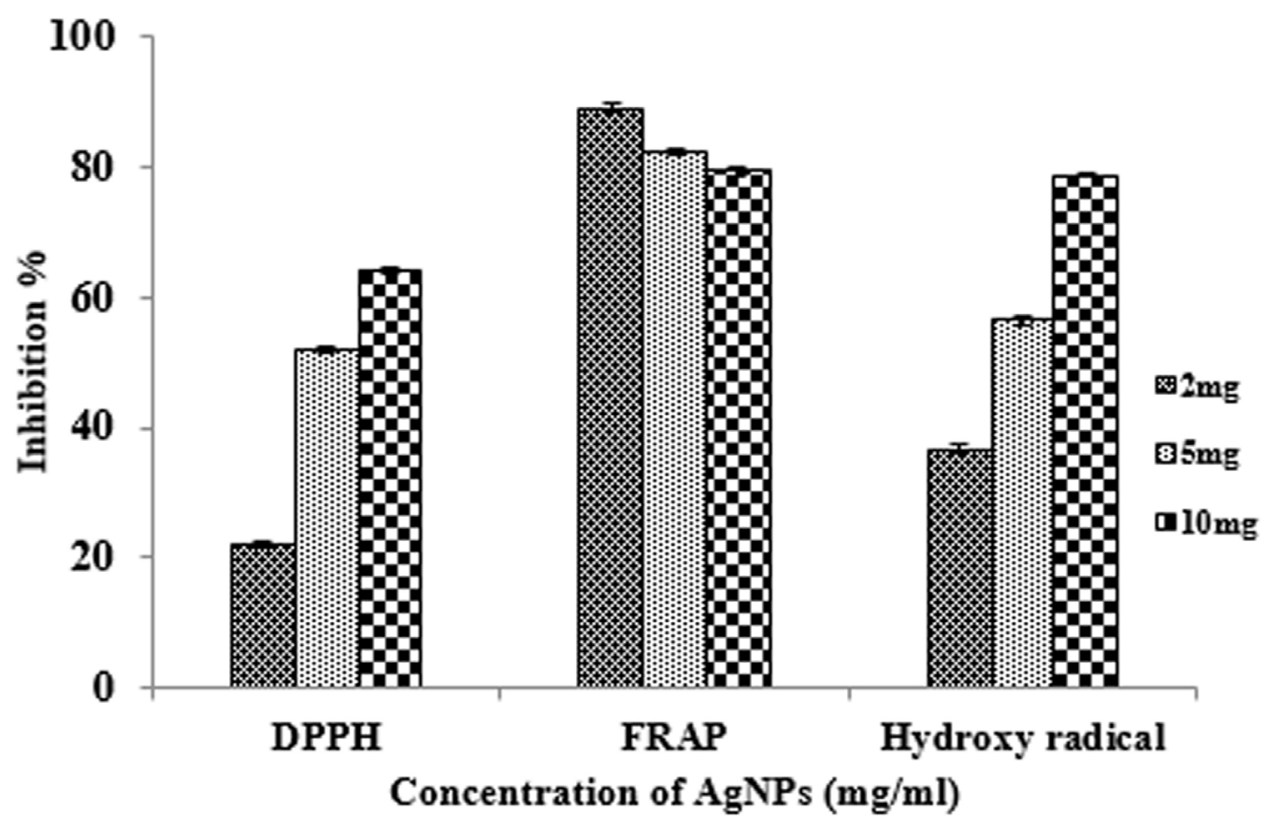

FIGURE 6 - Radical scavenging activity of synthesized silver nanoparticles using Rothan date seed extract.

\section{Anti-inflammatory and antiarthritic activity on synthesized AgNPs}

Research has proved that inflammation is the primary physiological defense mechanism against different stimuli and proteins denaturation is the primary cause for the onset of inflammation and arthritic diseases (Khader et al., 2018b). The inflammatory response is due to the cellular activity caused by action of lysosomal enzymes to an external stimuli. Figure 7 depicts the percentage inhibition of synthesized silver nanoparticles against membrane protein denaturation considerably reducing the effect of inflammation gradually above $250 \mu \mathrm{g} / \mathrm{mL}$ concentration. At $500 \mu \mathrm{g} / \mathrm{mL}$ concentration the percentage inhibition was found to be $63.32 \%$, and the $\mathrm{IC}_{50}$ value was above $100 \mu \mathrm{g} / \mathrm{mL}$ exhibiting good anti-inflammatory activity. The study of Kehili et al., (2016) represented anti-inflammatory activity using date 
fruits and seeds, our results prove AgNPs synthesised from Rothan date seeds is efficient against inflammation by membrane stabilisation and can be better cure after further exploration using animal model.

The results of the antiarthritic study reveals that percentage inhibition of synthesized silver nanoparticles increases with increase in concentration and the higher percentage inhibition was found to be $68.44 \%$ at $500 \mu \mathrm{g} /$ $\mathrm{mL}$ concentration (Figure 8). Hence, proving that the synthesized AgNPs inhibits protein denaturation there by inhibiting auto antigen production the main cause for the onset of inflammation leading to arthritis. The $\mathrm{IC}_{50}$ value was above $100 \mu \mathrm{g} / \mathrm{mL}$ and the silver nanoparticles exhibited good anti-arthritic activity. As in the previous study of Shravan kumar et al. (2011) reported antiarthritic activity of leaves of Physalis angulta. L. was $53.8 \%$. Similarly, synthesized silver nanoparticles has higher potential to be a remedy against arthritis.

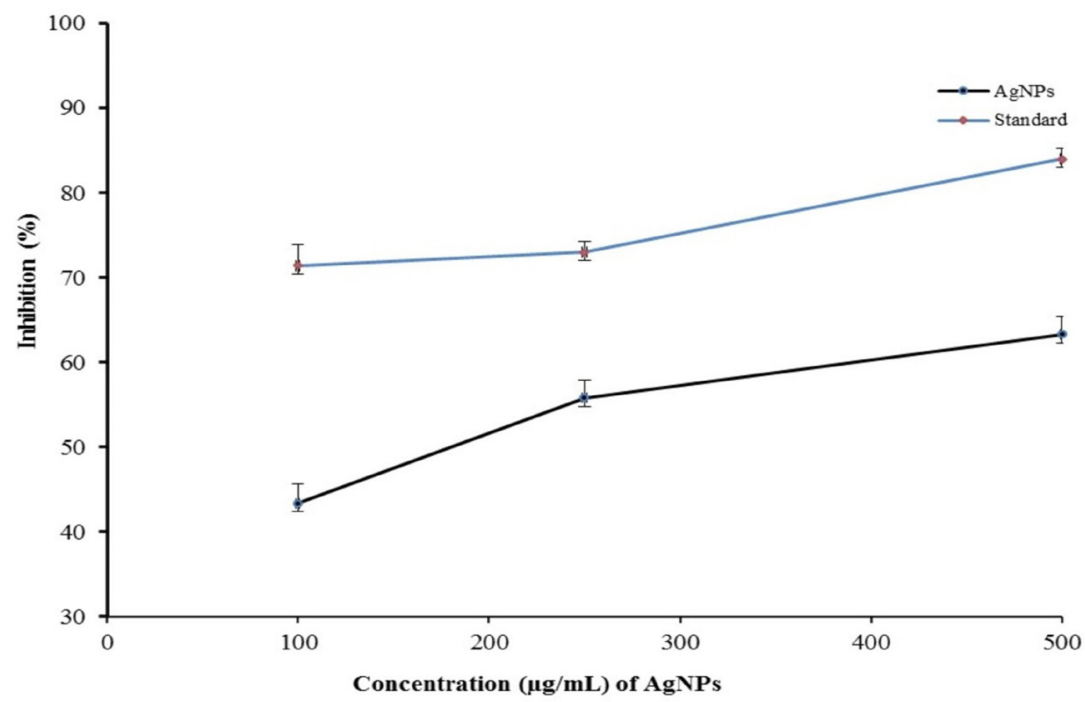

FIGURE 7 - Anti-inflammatory activity of synthesized silver nanoparticles using Rothan date seed extract.

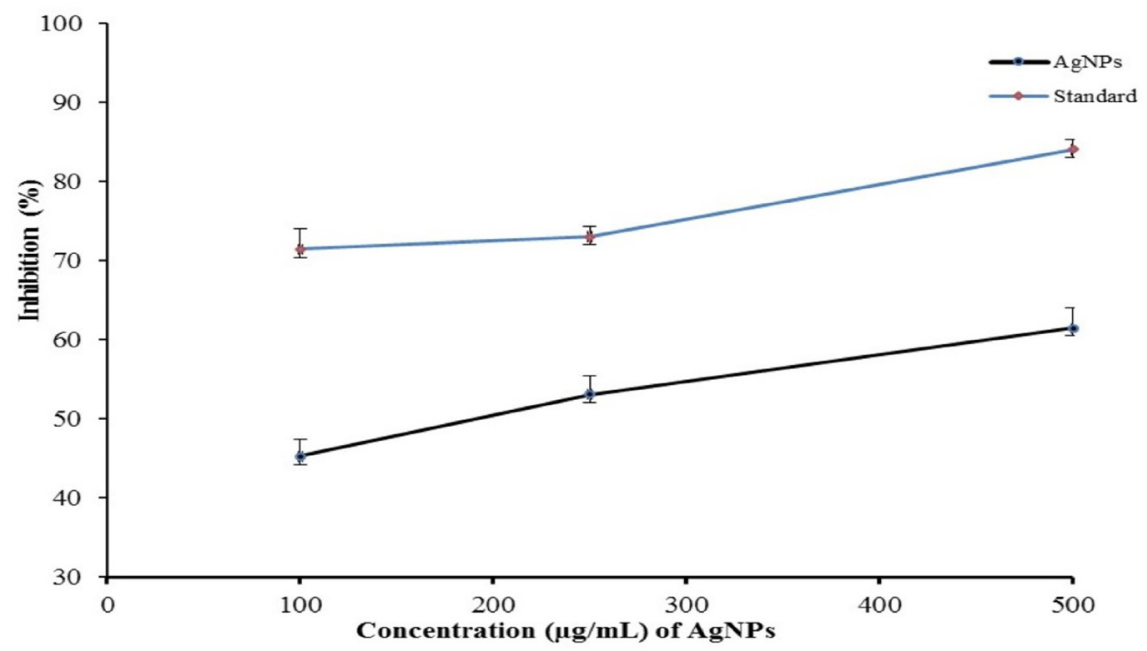

FIGURE 8 - Antiarthritic activity of synthesized silver nanoparticles using Rothan date seed extract. 


\section{Anticancer activity of synthesized AgNPs}

Cancer causes mortality and morbidity with a major health problem worldwide (Arunachalam et al., 2020; Khader et al., 2020). Therapeutic demand is increasing for cancer and Nanomaterials is an expected hope for diagnosis of cancer and therapy (Rosarin et al., 2013). Anticancer activity of green synthesized silver nanoparticles using Rothan date seed extract was analysed using lung (A549) adeno carcinoma cell lines. Cytotoxic analysis was performed from lower to higher concentration. Inhibiting concentration $\left(\mathrm{IC}_{50}\right)$ and morphological changes was observed at $100 \mu \mathrm{g} /$ $\mathrm{mL}$ and the results revealed that green synthesized silver nanoparticles has cytotoxicity effect in lung cancer cell line Figure 9. At $50 \mu \mathrm{g} / \mathrm{mL}$ concentration, synthesized AgNPs exhibited $77 \%$ of cell growth inhibition (Figure 10). The cell growth inhibition was $59 \%$ when treated with $100 \mu \mathrm{g} / \mathrm{mL}$ concentration of synthesized silver nanoparticles with an $\mathrm{IC}_{50}$ value of $59.66 \mu \mathrm{g} / \mathrm{mL}$. The results of the present study reveals that green synthesized silver nanoparticles with Rothan date seed extract produced significant cytotoxic effect against human lung cancer line and are in agreement with the previous studies with AgNPs used plant extracts tested against cancer cell lines (Venugopal et al., 2017). The cytotoxicity effect of AgNPs might be due to the stimulation of reactive oxygen species leading to disruption of cellular components of cancer cell and cell death (Dhand et al., 2016).
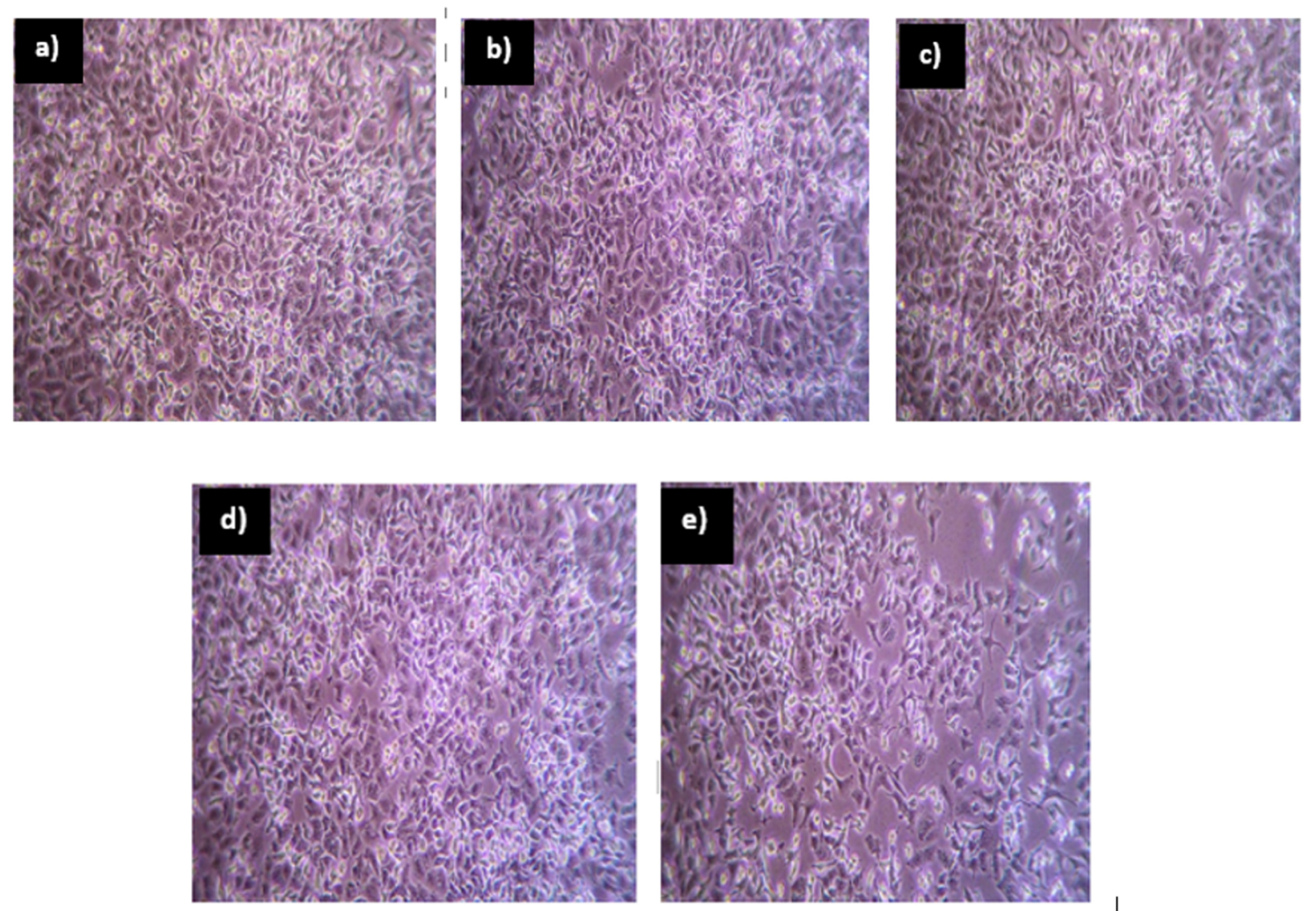

FIGURE 9 - The anticancer activity of lung cancer cell line images a) $6.25 \mu \mathrm{g} / \mathrm{mL}$, b) $12.5 \mu \mathrm{g} / \mathrm{mL}$, c) $25 \mu \mathrm{g} / \mathrm{mL}$, d) $50 \mu \mathrm{g} / \mathrm{mL}$ and e) $100 \mu \mathrm{g} / \mathrm{mL}$ of synthesized silver nanoparticles from Rothan date seed extract. 


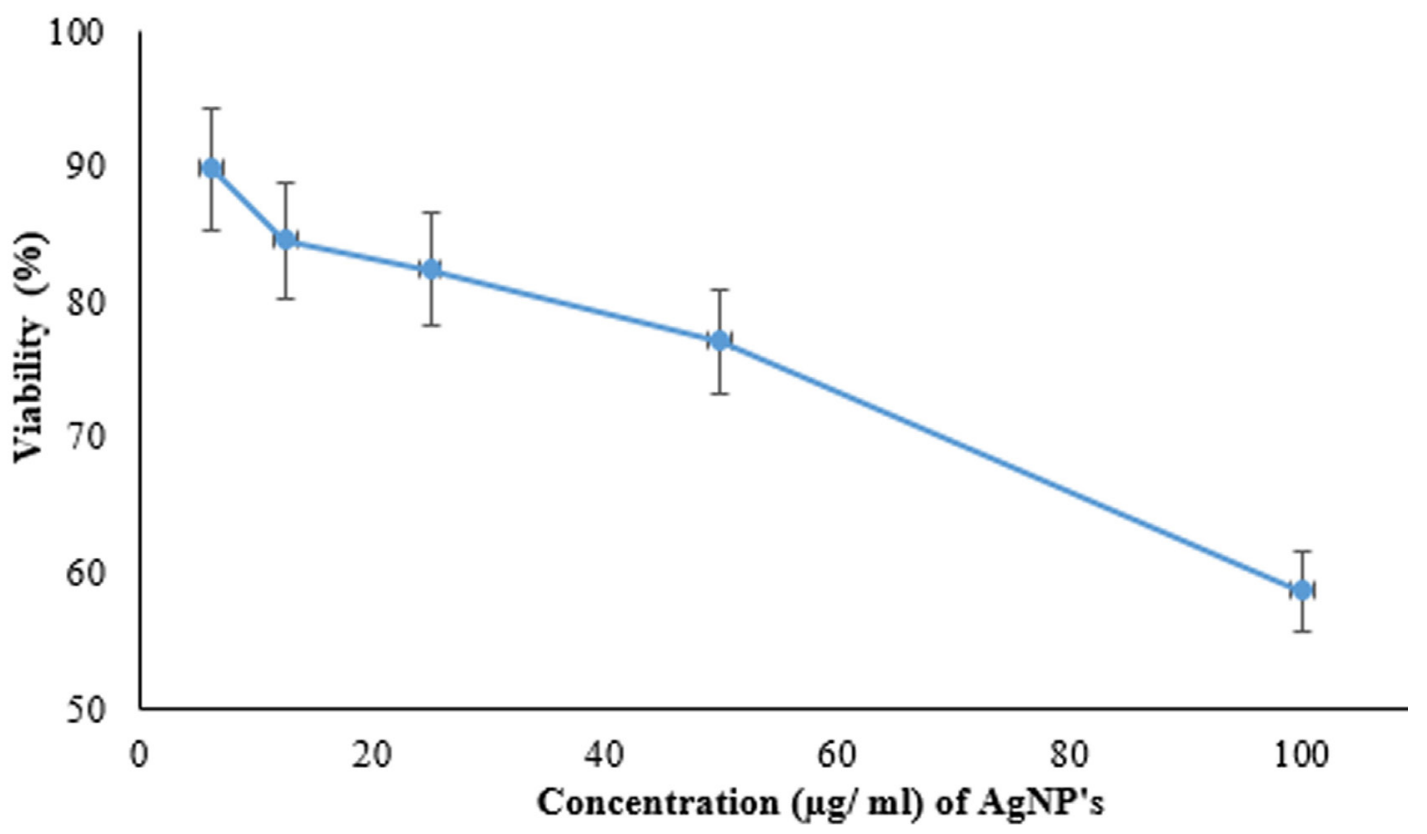

FIGURE 10 - The percentage of cell viability of synthesized silver nanoparticles from Rothan date seed extract.

\section{CONCLUSION}

The present study reveals the traditional usage of date fruits and its seeds as a better remedy for various ailment. A novel method is used to synthesise AgNPs from Phoenix dactylifera (Rothan) date seed extract and characterised using spectral data. The functional group present in the AgNPs were indented using FTIR, HRTEM and DLS represented the size, shape and distribution of AgNPs, crystallinity of AgNPs was examined using XRD. In-vitro analysis of silver nanoparticles over arthritis and inflammation represents a better cure by inhibiting protein denaturation the major cause for the onset of inflammation leading to arthritis. The cytotoxic studies using lung (A549) cancer cell line revealed the anti-proliferative property of AgNPs from Rothan date seed extract illustrated a potent cytotoxic effect. Hence proving the verdicts from Holy Quran that dates has a potential contribution in dietary supplement and as a medicine.

\section{CONFLICT OF INTERESTS}

The authors declare no conflict of interests.

\section{ACKNOWLEDGEMENT}

Authors are thankful to the Management and Principal of K.S.Rangasamy College of Technology, Tiruchengode (DBT- FIST and DBT- STAR Scheme) for providing infrastructure and facilities to carry out this research work successfully.

\section{REFERENCES}

Ahmed S, Saifullah, Ahmad M, Swami BL, Ikram S. Green synthesis of silver nanoparticles using Azadirachta indica aqueous leaf extract. J Radiat Res Appl Sci. 2016;6:42-47. doi.org/10.1016/j.jrras.2015.06.006

Arunachalam T, Khader SZA, Syed Zameer Ahmed S, Vetrivel M, SyedAmeen S, Ameer Khadharu IS, et al. Radical scavenging and antiproliferative effect of novel phenolic derivatives isolated from Nerium indicum against human breast cancer cell line (MCF-7)-an in silico and in vitro approach. Environ Sci Pollut Res. 2020;27(9):90389057. doi.org/10.1007/s11356-019-07252-x

Baghizadeh A, Ranjbar S, Gupta VK, Asif M, Pourseyedi S, Karimi MJ, et al. Green synthesis of silver nanoparticles using seed extract of Calendula officinalis in liquid phase. J Mol Liq. 2015;207:159-163. doi.org/10.1016/j.molliq.2015.03.029 
Banerjee P, Satapathy M, Mukhopahayay A, Das P. Leaf extract mediated green synthesis of silver nanoparticles from widely available Indian plants: synthesis, characterization, antimicrobial property and toxicity analysis. Bioresour, Bioprocess. 2014;1(3):1-10. doi.org/10.1186/s40643-0140003-y

Deshpande V, Jadhav VM, Kadam VJ. In vitro anti-arthritic activity of Abutilon indicum (Linn.) Sweet. J Pharm Res. 2009;2(4):644-645.

Dhand V, Soumya L, Bharadwaj S, Chakra S, Bhatt D, Sreedhar B. Green Synthesis of silver nanoparticles using Coffea arabica seed extract and its antibacterial activity. Mater Sci Eng. 2016;58:36-43. doi.org/10.1016/j. msec.2015.08.018

Farhadi S, Ajerloo B, Mohammadi A. Green biosynthesis of spherical Silver nanoparticles by using Date Palm (Phoenix Dactylifera) fruit extract and study of their antibacterial and catalytic activities. Acta Chim Slov. 2017;64(1):129-143. doi.10.17344/acsi.2016.2956

Haghighi Pak Z, Abbaspour H, Naser Karimi N, Fattahi A. Eco-Friendly Synthesis and Antimicrobial Activity of Silver Nanoparticles Using Dracocephalum moldavica Seed Extract. Appl Sci. 2016;6:69. doi.org/10.3390/app6030069

HalliwellB, John MC Gutteridge, Aruoma OI. The deoxyribose method: a simple test tube assay for the determination of rate constants for reactions of hydroxyl radicals. Anal Biochem. 1987;165(1):215-219. doi.org/10.1016/0003-2697(87)90222-3

Jayaseelana C, Ramkumar R, Rahumana AA, Perumal P. Green synthesis of gold nanoparticles using seed aqueous extract of Abelmoschus esculentus and its antifungal activity. Ind Crops Prod. 2013;45:423-429. doi.org/10.1016/j. indcrop.2012.12.019

Kehili HE, Zerizer S, Beladjila KA, Kabouche Z. Antiinflammatory effect of Algerian date fruit (Phoenix dactylifera). Food Agric Immunol. 2016;27(6):820-829. doi. org/10.1080/09540105.2016.1183597

Khader SZA, Syed Zameer Ahmed S, Ganesan GM, Mahboob MR, Vetrivel M, Sankarappan M, et al. Rhynchosia rufescens AgNPs enhance cytotoxicity by ROS-mediated apoptosis in MCF-7 cell lines. Environ Sci Pollut Res. 2020;27:2155-2164. doi.org/10.1007/s11356-019-06479-y

Khader SZA, Syed Zameer Ahmed S, Sathyan J, Mahboob MR, Venkatesh KP, Ramesh K. A comparative study on larvicidal potential of selected medicinal plants over green synthesized silver nano particles. Egypt J Basic Appl Sci. 2018a;5(1):54-62. doi.org/10.1016/j.ejbas.2018.01.002

Khader SZA, Syed Zameer Ahmed S. Arunachalamb T, Sanjeeva N, Balasubramanian SK SyedAmeen ST, et al. Radical scavenging potential, antiinflammatory and antiarthritic activity of isolated Isomer Methyl- $\gamma$-Orsellinate and Roccellatol from Roccella Montagnei. Bulletin of Faculty of Pharmacy, Cairo University, 2018b;56(1):39-45. doi.org/10.1016/j.bfopcu.2018.02.001

Mizushima Y, Kobayashi M. Interaction of anti-inflammatory drugs with serum proteins, especially with some biologically active proteins. J Pharm Pharmacol. 1968;20(3):169-173. doi. org/10.1111/j.2042-7158.1968.tb09718.x

Oyaizu M. Studies on products of browning reactions prepared from glucosamine. Japanese $\mathrm{J}$ Nutrition. 1986;44(6):307-315. doi.org/10.5264/eiyogakuzashi.44.307

Packialakshmi N, Suganya C, Guru V. Antibacterial activity and green synthesis of silver nanoparticles using Strychnos potatorum seed and bark extract. Asian J Phytomed Clin Res. 2014;2(3):127-138.

Rafi MM, Ahmed KSZ, Nazeer KP, Kumar SD, Thamilselvan M. Synthesis, characterization and magnetic properties of hematite $\left(\alpha-\mathrm{Fe}_{2} \mathrm{O}_{3}\right)$ nanoparticles on polysaccharide templates and their antibacterial activity. Appl Nanosci. 2015;5:515-520. doi.org/10.1007/s13204-014-0344-z

Rosarin FS, Arulmozhi V, Nagarajan S, Mirunalini S. Antiproliferative effect of silver nanoparticles synthesized using amla on Hep2 cell line. Asian Pac J Trop Med. 2013;6(1):1-10. doi.org/10.1016/S1995-7645(12)60193-X

Roy A, Bulut O, Some S, Mandal AK, Yilmaz DM. Green synthesis of silver nanoparticles: biomolecule-nanoparticle organizations targeting antimicrobial activity. RSC Adv. 2019;9:2673-2702. doi.org/10.1039/C8RA08982E

Shankar SS, Rai A, Amad A, Sastry M. Rapid synthesis of $\mathrm{Au}, \mathrm{Ag}$, and bimetallic Au core - Ag shell nanoparticles using Neem (Azadirachta indica) leaf broth. J Colloid Interface Sci. 2004;275(2):496-502. doi.org/10.1016/j.jcis.2004.03.003

Shib SD, Arun KS, Braja GB, Sujoy B. Phoenix dactylifera (Date Palm) Seed Extract Mediated Green Synthesis of Gold Nanoparticles and its Application as a Catalyst for the Reduction of 4-nitrophenol to 4-aminophenol. Int J Nanomat Biostru. 2013;2(3):42-46.

Shimada K, Fujikawa KK, Yahara K, Nakamura T. Antioxidative properties of xanthan on the autoxidation of soybean oil in cyclodextrin emulsion. J Agric Food Chem. 1992;40(6):945-948. doi. 10.1021/jf00018a005

Shravan Kumar N, Kishore G, Siva Kumar G, Sindhu Priya ES. In vitro anti-inflammatory and anti-arthritic activity of leaves of Physalis angulata L. Int J Pharm Ind Res. 2011;1(3):211-213.

Sidhra S, Syed Zameer Ahmed K, Krishnaveni R, Anupriya B, Senthil Kumar B, Kishore R. Modulatory effect of Leucas aspera on oxidative stress and glucose metabolism against 
diabetic complications in experimental rats. Int Res J Pharm. 2017;8(8):27-33. doi.10.7897/2230-8407.088140

Syed Zameer Ahmed K, Sidhra S, Thangakumar A, Krishnaveni R. Therapeutic effect of Parmotrema tinctorum against complete Freund's adjuvant-induced arthritis in rats and identification of novel Isophthalic ester derivative. Biomed Pharmacother. 2019a;112:108646. doi.org/10.1016/j. biopha.2019.108646

Syed Zameer Ahmed S, Khader SZA, Radhakrishnana $\mathrm{K}$, Marimuthua V, Chinnusamy M, Thangavel V, et al. Antiobesity and antihyperlipidemic effect of Ixora coccinea on triton-X100 induced hyperlipidemia in rats- an approach to evaluate Asymmetrical Temperature Distribution Analysis Using Thermography. Chinese Herbal Medicines. 2019b;11(3):326-331 doi.org/10.1016/j.chmed.2019.05.006

Venugopal K, Rather HA, Rajagopal K, Shanthi MP, Sheriff $\mathrm{K}$, Illiyas M, et al. Synthesis of silver nanoparticles (AgNPs) for anticancer activities (MCF 7 breast and A549 lung cell lines) of the crude extract of Syzygium aromaticum. J Photochem Photobiol B. 2017;167:282-289. doi.org/10.1016/j. jphotobiol.2016.12.013

Received for publication on $27^{\text {th }}$ July 2019 Accepted for publication on $27^{\text {th }}$ August 2019 